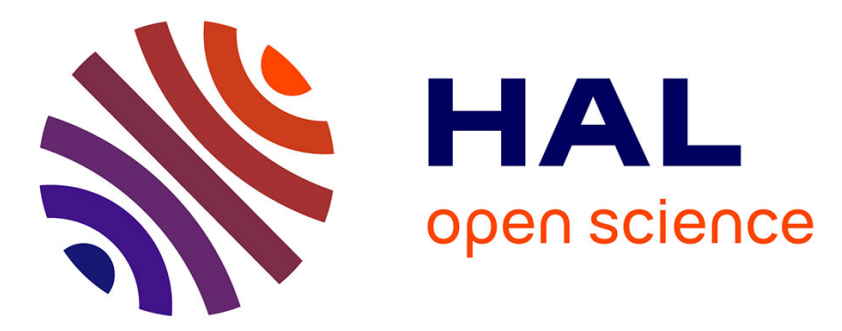

\title{
Nanoscale tunable reduction of graphene oxide for graphene electronics
}

\author{
Z. Wei, D. Wang, Suenne Kim, S. Y. Kim, Yike Hu, M. K. Yakes, A.R. \\ Laracuente, Z. Dai, S.R. Marder, Claire Berger, et al.
}

\section{- To cite this version:}

Z. Wei, D. Wang, Suenne Kim, S. Y. Kim, Yike Hu, et al.. Nanoscale tunable reduction of graphene oxide for graphene electronics. Science, 2010, 328 (5984), pp.1373-1376. 10.1126/science.1188119 . hal-01003133

\section{HAL Id: hal-01003133 \\ https://hal.science/hal-01003133}

Submitted on 9 Jun 2014

HAL is a multi-disciplinary open access archive for the deposit and dissemination of scientific research documents, whether they are published or not. The documents may come from teaching and research institutions in France or abroad, or from public or private research centers.
L'archive ouverte pluridisciplinaire HAL, est destinée au dépôt et à la diffusion de documents scientifiques de niveau recherche, publiés ou non, émanant des établissements d'enseignement et de recherche français ou étrangers, des laboratoires publics ou privés. 


\title{
Nanoscale tunable reduction of graphene oxide for graphene electronics
}

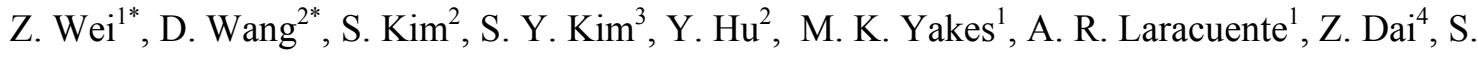 \\ R. Marder ${ }^{3}$, C. Berger ${ }^{2,5}$, W. P. King ${ }^{4}$, W. A. de $\operatorname{Heer}^{2}$, P. E. Sheehan ${ }^{1 \dagger}$, E. Riedo ${ }^{2 \dagger \dagger}$ \\ ${ }^{1}$ Chemistry Division, U.S. Naval Research Laboratory, Code 6177, Washington, D.C. 20375, USA \\ ${ }^{2}$ School of Physics, Georgia Institute of Technology, Atlanta, Georgia 30332, USA \\ ${ }^{3}$ School of Chemistry and Biochemistry, Georgia Institute of Technology, Atlanta, Georgia 30332, USA \\ ${ }^{4}$ Department of Mechanical Science and Engineering, University of Illinois Urbana-Champaign, USA \\ ${ }^{5}$ CNRS-Institut Néel, BP166, 38042 Grenoble Cedex 9, France \\ *These authors contributed equally to this work. \\ †paul.sheehan@nrl.navy.mil ${ }^{\dagger \dagger}$ elisa.riedo@physics.gatech.edu
}

Graphene is now recognized as the most likely carbon-based successor material for CMOS electronics. Recently, interest in graphene oxide (GO) has risen for producing large-scale flexible conductors and for its potential to open an electronic gap in graphene structures. We report on a means to tune the topographical and electrical properties of graphene-based materials with nanoscopic resolution by local thermal reduction of GO with a nano-size tip. The reduced GO nanostructures show an increase in conductivity up to four orders of magnitude as compared to pristine GO. No sign of tip wear or sample tearing was observed. Variably conductive nanoribbons with dimensions down to $12 \mathrm{~nm}$ have been produced in oxidized epitaxial graphene films in a single step that is clean, rapid and reliable. 
Graphene's high electronic mobility (1-3), gating capability (4-6), and bandgap tuning potential $(1,7,8)$, have motivated large scale device patterning in epitaxial graphene $(9)$, leading to transistors operating at $\mathrm{GHz}$ frequency (10). Techniques to produce nanometer scale graphene structures include e-beam lithography $(1,6,11)$, chemical exfoliation (7), local anodic oxidation lithography (12), and carbon nanotube unzipping (13). Routine fabrication of graphene-based nanostructures over large areas is challenging in terms of reproducibility, resolution, robustness, edges control, substrate compatibility, and scalability. Recently, reduction of graphene oxide (GO), an insulating material with a transport gap larger than $0.5-0.7 \mathrm{eV}$ at room temperature, has been indicated as a promising route for translating the interesting fundamental properties of graphene into technologically viable devices $(14,15)$, such as transparent electrodes $(14)$, chemical sensors (16), and MEMS resonators (17). In particular, transport measurements have shown that GO undergoes an insulator-semiconductor-semimetal transition as it is reduced back to graphene $(15,18)$.

Here, we present a tip-based thermochemical nanolithography (TCNL) method, to directly control the reduction of GO, and thereby its conductivity, on the nanoscale. The reduced GO nanostructures show an increase in conductivity up to four orders of magnitude as compared to pristine GO. The method is fast (several $\mu \mathrm{m} / \mathrm{s}$ ), applies both to conducting and insulating substrates, and is reproducible. GO has been converted to a conductor with a $100 \%$ yield in dozens of structures patterned on random locations in the GO film. Reduced GO (rGO) patterns range from ribbons $12 \mathrm{~nm}$ in width (FWHM) up to 
$20 \mu \mathrm{m}$. No sign of tip wear or sample tearing was observed, indicating that the "carbon skeleton" is continuous across the $\mathrm{GO} / \mathrm{rGO}$ junction.

Thermochemical nanolithography with heated probe tips has successfully induced chemical reactions on a surface (19-21) or deposited material (22-24). Similar heated tips have also been used to mechanically modify a polymer film (25). The key advantage of these heated probe tips is the ability to localize a nanometer-scale hot spot with a resolution that cannot be achieved by other means. Herein, we demonstrate that TCNL can locally reduce graphene oxide sheets and thereby control their electronic properties (Fig. 1-3) without use of additional reagents. This thermochemical nanolithography is first validated on single layers of isolated graphene oxide and then shown to work equally well on large area $\mathrm{GO}$ films formed by on-chip oxidation of epitaxial graphene $\left(\mathrm{GO}_{\mathrm{epi}}\right)$ grown on SiC. The TCNL written nanoribbons have dimensions as small as $12 \mathrm{~nm}$. To date, all the GO reduction strategies $(15,26)$ have led to materials with some residual oxygen and structural defects and so the material is referred to as reduced graphene oxide rather than graphene. Chemical reduction has been particularly well studied, and it is known that exposure of GO to strong reducing agents such as hydrazine results in an increased electrical conductivity by three to four orders of magnitude (27). Recent studies have demonstrated that annealing at $450{ }^{\circ} \mathrm{C}$ or above is equivalent to chemical reduction via hydrazine monohydrate at $80^{\circ} \mathrm{C}$ followed by heating at $200^{\circ} \mathrm{C}(26)$. Thermal reduction of GO occurs already at moderate temperature $\left(100-250^{\circ} \mathrm{C}\right)$, and enables the tuning of the gap in graphene oxide (15), as demonstrated in the $\mathrm{I}(\mathrm{V})$ characteristics. Extensive reduction requires temperatures exceeding $450{ }^{\circ} \mathrm{C}(26)$. In the experiments 
presented in this report, the nanoscale thermal reduction of $\mathrm{GO}$ flakes and $\mathrm{GO}_{\mathrm{epi}}$ films (see (28) and Supporting Online Material) is achieved by means of a heated atomic force microscopy (AFM) probe (29). The TCNL reduction of GO is verified here by friction force microscopy (FFM), conductive AFM (CAFM), Raman spectroscopy, Kelvin probe force microscopy (KPFM), and UHV electronic transport measurements using a 2- and 4probe STM, (see Supporting Online Material for details on all these techniques).

To demonstrate TCNL reduction of GO, we begin with isolated $\mathrm{GO}$ flakes on a $\mathrm{SiO}_{\mathrm{x}} / \mathrm{Si}$ substrate (Figures 1 and 2). Arbitrary graphene features such as a cross (Fig. 1) or squares (Fig. 2) are reliably obtained by scanning the heated AFM tip over a GO sheet. The thermal reduction decreases the $9.5 \pm 1.9 \AA$ height of the sheet by $2-5 \AA$, as obtained from the topography image shown in Figure 1 and Figure S6 in the Supporting Online Material. The reasons for this height reduction are two-fold. First it is the loss of oxygen rich functional groups from the flake surface. Given that scanning an unheated tip does not result in height changes, this loss is primarily caused by intrinsic chemical conversion rather than mechanical removal. It is not possible, however, to rule out tribochemical effects at elevated temperatures. Secondly, the conversion of GO's $s p^{3}$ carbon bonds into $s p^{2}$ carbon bonds will flatten the material since the $s p^{3}$ carbon bonds in GO ripples the carbon skeleton thereby increasing the sheet thickness $(14,30,31)$. The conversion per se of these $s p^{3}$ bonds to planar $s p^{2}$ bonds will also flatten the structure; however, height measurements alone are insufficient to determine the relative contributions of these two effects. 
An important goal of this work was to demonstrate variable reduction of GO. Friction measurements show that this could be achieved by controlling the temperature of the AFM tip. Graphene has a low friction coefficient (32) while oxides typically have higher friction coefficients. Consequently, thermal reduction should also reduce friction as the high friction GO is replaced with lower friction graphene. Figure 2 shows the strong correlation between the cantilever temperature during TCNL processing and the lateral force on a room temperature tip scanned over previously reduced squares. While the cantilever temperature can be precisely determined, the contact temperature must be modeled (see Supporting Online Material). The reported temperatures are the cantilever temperatures. Reduction begins at or above $130{ }^{\circ} \mathrm{C}$ which is comparable to the results of Wu et al. and Mattevi et al. that showed that reduction starts at $100{ }^{\circ} \mathrm{C}(15,26)$ presumably after the desorption of adventitious water. Higher temperatures increased the rate of reduction as shown by the roughly linear decrease in relative friction with temperature.

Although isolated GO flakes are suited for basic studies of the process, further technological development requires extended films of GO. Large area $\mathrm{GO}_{\text {epi }}$ films $(>15$ $\mathrm{mm}^{2}$ ) are obtained by oxidizing multilayer epitaxial graphene (EG) grown on the carbon face of $\mathrm{SiC}(28)$. The oxidized films consist of multiple high-quality $\mathrm{GO}_{\text {epi }}$ layers that completely cover the $\mathrm{SiC}$ surface. AFM images show no tearing in the $\mathrm{GO}_{\text {epi }}$ films indicating that they maintain their structural integrity when exposed to the harsh oxidation conditions. Figures 3 and 4 show the results obtained by performing TCNL on a $\mathrm{GO}_{\text {epi }}$ film with a thickness of about $25 \pm 5 \mathrm{~nm}$, as determined by AFM by scratching 
away $\mathrm{GO}_{\text {epi }}$ from the $\mathrm{SiC}$ substrate. Figure 3 presents a zigzag $\mathrm{rGO}_{\text {epi }}$ nanoribbon written with a single line scan at $T_{\text {heater }} \sim 1060{ }^{\circ} \mathrm{C}$ on $\mathrm{GO}_{\text {epi. }}$. Figure 3a is an image of the current measured between a conductive platinum AFM tip and each point of the surface, showing no current on the GO surface and a current enhancement of about $100 \mathrm{pA}$ in the $\mathrm{rGO}_{\mathrm{epi}}$ nanoribbons. These current values are consistent with the presence of $12 \mathrm{~nm}$ wide and several nanometers thick $\mathrm{rGO}_{\mathrm{epi}}$ nanoribbons presenting a vanishingly small Schottky barrier; and a resistive $\mathrm{SiC}$ substrate (resistivity of about $10^{5} \Omega \mathrm{cm}$ ). For a $25 \mathrm{~nm}$ thick GO film locally heated by a tip at $1000{ }^{\circ} \mathrm{C}$, heat flow through the layers might reduce most of the GO underneath the tip leaving only a few layers of unreduced GO at the $\mathrm{SiC}$ interface (see Supporting Online Material). The topographical image (Fig. 3b and black graph in Fig. 3c) indicates that the reduction produces a shallow indentation of $1 \mathrm{~nm}$ whose origin has been previously discussed for the isolated GO sheets.

We further investigated the electrical properties of the locally reduced $\mathrm{GO}_{\text {epi }}$ structures using KPFM and 4-point transport measurements in a UHV Omicron Nanoprobe system (see Supporting Online Material). In the 4-point transport measurements (Fig. 4a and 4b), we measured the sheet resistance, $R_{\text {sheet }}$, of $20 \times 20 \mu \mathrm{m}^{2}$ squares of TCNL $\mathrm{rGO}_{\text {epi }}$ and found that $R_{\text {sheet }}$ decreased with increasing temperature used for the TCNL local reduction, up to four orders of magnitude lower than the resistance of the original $\mathrm{GO}_{\mathrm{epi}}(15)$. The same significant increase of the in-plane conductivity is observed for extended films of $\mathrm{rGO}_{\text {epi }}$ produced by overnight heating of $\mathrm{GO}_{\text {epi }}$ in a furnace at $600{ }^{\circ} \mathrm{C}$. Furthermore, we found that $R_{\text {sheet }}$ and the shape of the I(V) characteristics can be varied by changing the temperature of the AFM probe (see Fig. 4a and 4b), consistent with a change in the 
transport gap from $0.5 \mathrm{eV}$ to vanishingly small. These results are consistent with KPFM measurements showing that the TCNL reduced $\mathrm{GO}_{\text {epi }}$ displays a contact potential change of $168 \pm 54 \mathrm{mV}$ in respect to $\mathrm{GO}_{\mathrm{epi}}$. Due to the residual oxygen and structural disorder, we observe a large difference in conductivity between epitaxial graphene and $\mathrm{rGO}_{\mathrm{epi}}$ or TCNL-rGO

Having established that heated tips achieved reductions comparable to global heating treatments, we extended the analysis to an isolated TCNL-rGO epi nanoribbon (Fig. 4c).

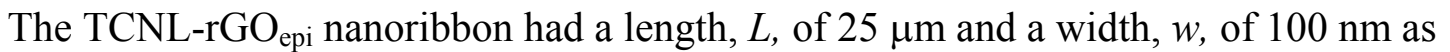
measured by AFM. Current versus voltage data were acquired in the Omicron Nanoprobe system by placing the conductive tips on top of two micron-size squares of $\mathrm{rGO}_{\mathrm{epi}}$ fabricated in situ by an electron beam at each end of the nanoribbon (Fig. 4c). These pads ensured good electrical contact with the narrow ribbon. Two point transport measurements indicated a resistance larger than $2 \mathrm{G} \Omega$ when the tips were positioned on an arbitrary position on the GO surface (very large barrier at the contact) and a drop in resistance from $120 \mathrm{M} \Omega$ (between the 2 squares with no nanoribbon) to $20 \mathrm{M} \Omega$ (between the 2 squares connected by the nanoribbon). More importantly the transport behavior changes from insulating to ohmic (linear $\mathrm{I}(\mathrm{V})$ curves) in presence of the TCNL-rGO $\mathrm{epi}$ nanoribbon between the squares (Fig. 4c). By using the relationship $R_{\text {sheet }}=$ $\left(R_{\text {ribbon }} \cdot w \cdot t_{\text {ribbon }}\right) /\left(L \cdot t_{\text {sheet }}\right)(33)$, and assuming a $13 \mathrm{~nm}$ thick nanoribbon, we obtain a sheet resistance of $65 \mathrm{k} \Omega$, in very good agreement with the measurements reported in Fig. $4 \mathrm{a}$, and $\mathrm{b}$ for microscopic squares of TCNL-rGO $\mathrm{epi}_{\text {. }}$ 
A tip-based thermochemical nanolithography has been developed to directly control the electrical properties of $\mathrm{GO}$ on the nanoscale at speeds of several micrometers per seconds. Arbitrary shapes of reduced GO features can be produced by this technique. Compared to the starting GO, the rGO nanostructures, with widths down to $12 \mathrm{~nm}$, show an increase in conductivity up to four orders of magnitude and a change in the shape of the I(V) characteristics. Dozens of arbitrarily shaped rGO features have been produced in arbitrarily chosen positions in the GO films, with a 100 percent yield, demonstrating the good reproducibility of the technique. The size of the rGO structures shown here was continuously varied between $12 \mathrm{~nm}$ (FWHM width of a nanoribbon) up to $20 \mu \mathrm{m}$. No sign of tip wear or sample tearing was observed, indicating that the "carbon skeleton" is continuous across the $\mathrm{GO} / \mathrm{rGO}$ junction. As a result, extrinsic effects such as impurities, and interface layers, are likely obviated. Critically, TCNL does not require any solvents or lithographic resists that could contaminate the sample. This is especially important since the electronic properties of graphene are known to vary strongly with surface doping. Furthermore, the heatable probe enables in situ metrology of the fabricated nanostructures, such as friction, and Raman measurements. TCNL applied to large scale $\mathrm{GO}$ grown on $\mathrm{SiC}$ is a reliable, high resolution, no tearing technique which can be applied to conductive and non conductive substrates and which preserves the continuity of the carbon skeleton. The strategy of variably reducing extended GO films is a general one that could be implemented in multiple ways depending on the application. The manufacture of graphene nanoelectronics could be achieved by using arrays of heated probe tips (25). Independently addressed heated probe tips could alternately read or write 
nanostructures on a surface and in large arrays could address wafer-scale areas at high speed. A nano-embossing approach might also achieve local GO reduction, provided that the imprint template would offer nanometer-scale control of the reducing temperature field (34).

\section{Competing Financial Interests}

The authors declare that they have no competing financial interests. 


\section{Figure legends}

Fig. 1. Local thermal reduction of a single-layered graphene oxide flake. (A)

Topography of a cross shape of reduced GO formed after an AFM tip heats the contact to $330{ }^{\circ} \mathrm{C}$ scanned across the $\mathrm{GO}$ sheet at $2 \mu \mathrm{m} / \mathrm{s}$. (B) Zoom out topographical top view of the same sheet as that in (A). (C) The averaged profile of the trench outlined in (B) shows that the width (FWHM) of the line can be as narrow as $25 \mathrm{~nm}$.

Fig. 2. The rate of thermal reduction depends on the tip temperature. The plot shows the decrease in lateral force on an AFM tip at room temperature as it scans over several squares previously reduced by TCNL at different temperatures. The inset is a room temperature friction image of the GO sheet on which a heated tip was previously rastered twice over six square areas, at a speed of $4 \mu \mathrm{m} / \mathrm{s}$. In square 1 , the tip was heated during TCNL to $T_{\text {heater }} \sim 100{ }^{\circ} \mathrm{C}$ yielding no apparent reduction while at temperatures $T_{\text {heater }}$ $>150{ }^{\circ} \mathrm{C}$ the rastered areas (2-6) were thermally reduced. Reduced GO, which like bulk graphite behaves as a lubricant, shows lower friction than the original GO. Higher temperatures accelerate the thermal reduction of GO and thereby more rapidly lower friction.

Fig. 3. Local thermal reduction of a $\mathrm{GO}_{\text {epi }}$ film: current and topographical images. (A) 3D room temperature AFM current image (taken with a bias voltage of $2.5 \mathrm{~V}$ between tip and substrate) of a zigzag shaped nanoribbon fabricated by TCNL on $\mathrm{GO}_{\text {epi }}$ at $T_{\text {heater }} \sim$ $1060{ }^{\circ} \mathrm{C}$, with a linear speed of $0.2 \mu \mathrm{m} \mathrm{s}^{-1}$ and a load of $120 \mathrm{nN}$. (B) Corresponding 
topography image taken simultaneously with (A). (C) Averaged profiles of current and height of the cross sections that are indicated as dashed lines in (B).

Fig. 4. 4 and 2-point transport measurements and Kelvin probe force microscopy. (A) Current-voltage curves obtained by 4-point transport measurements of TCNL lowtemperature reduced graphene oxide (Low $T, T_{\text {heater }} \sim 600^{\circ} \mathrm{C}$ ), TCNL high-temperature reduced graphene oxide (High $T, T_{\text {heater }} \sim 1200{ }^{\circ} \mathrm{C}$ ), and vacuum reduced graphene oxide at $600^{\circ} \mathrm{C}$. (B) This table presents the sheet resistance, $R_{\text {sheet }}$, measured by 4-point transport measurements, and the contact potential change $(\Delta \Phi)$ between $\mathrm{GO}_{\text {epi }}$ and each listed sample (EG, $\mathrm{rGO}_{\text {epi, }}$, and TCNL-rGO $\mathrm{epi}_{\text {, }}$ respectively). (C) Left. SEM images of the configuration used for 2-point transport measurements when the tips are positioned

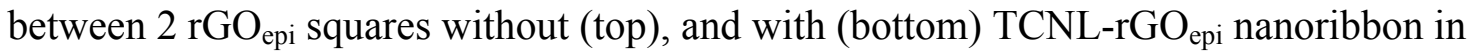
between. The AFM cross section of the nanoribbon is shown as inset of the bottom SEM image. Right. I(V) curves obtained measuring current between $2 \mathrm{rGO}_{\text {epi }}$ squares with no nanoribbon in between (top curve), and between $2 \mathrm{rGO}_{\text {epi }}$ squares with a nanoribbon in between (bottom curve). 


\section{Figures}

\section{Figure 1}
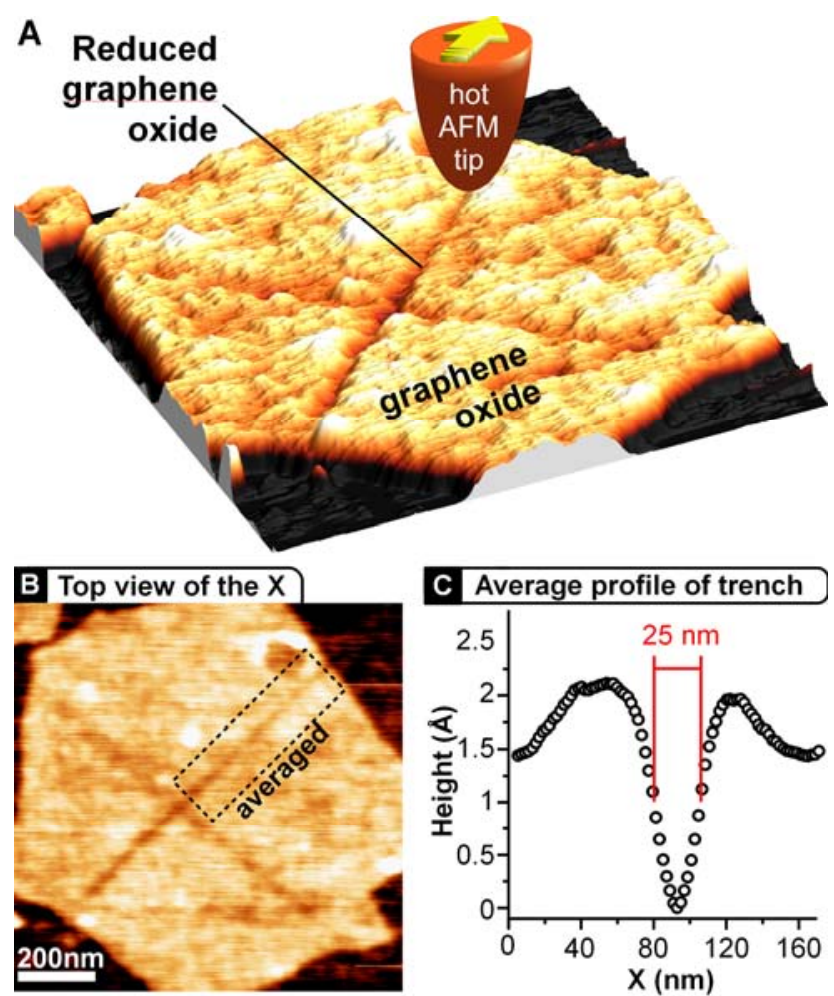
Figure 2

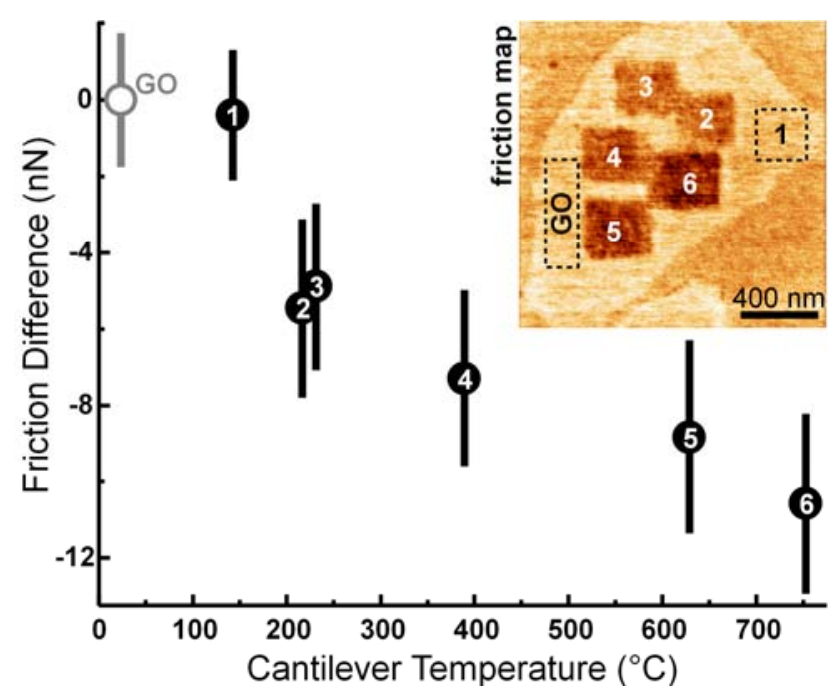


Figure 3
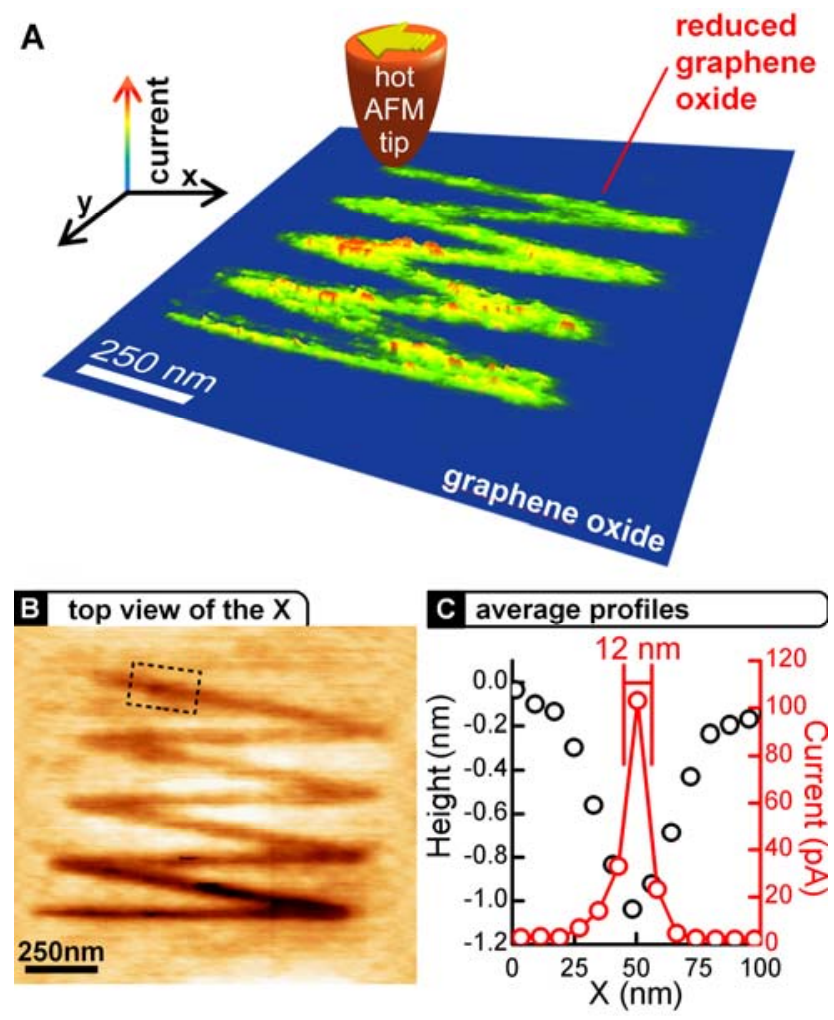


\section{Figure 4}

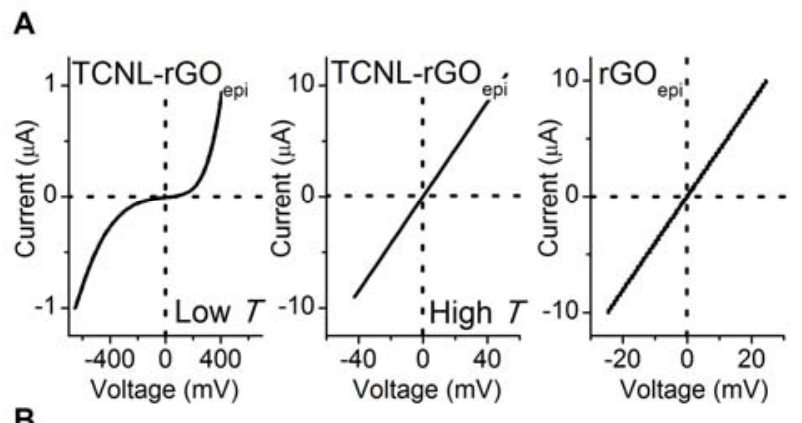

B

\begin{tabular}{|c|c|c|}
\hline Sample & $R_{\text {sheet }}$ & $\Delta \Phi$ \\
\hline EG & $50 \pm 47 \Omega$ & $290 \pm 61 \mathrm{mV}$ \\
\hline $\mathrm{GO}_{\text {epi }}$ & $427 \pm 11 \mathrm{M} \Omega$ & 0 \\
\hline TCNL-rGo $\mathrm{epi}$ low $T$ & $9174 \pm 2 \mathrm{~K} \Omega$ & $N / A$ \\
\hline TCNL-rGo epi ${ }_{\text {high } T}$ & $30 \pm 3 \mathrm{~K} \Omega$ & $168 \pm 54 \mathrm{mV}$ \\
\hline $\mathrm{rGO}_{\text {epi }}$ & $18 \pm 10 \mathrm{~K} \Omega$ & $188 \pm 96 \mathrm{mV}$ \\
\hline
\end{tabular}
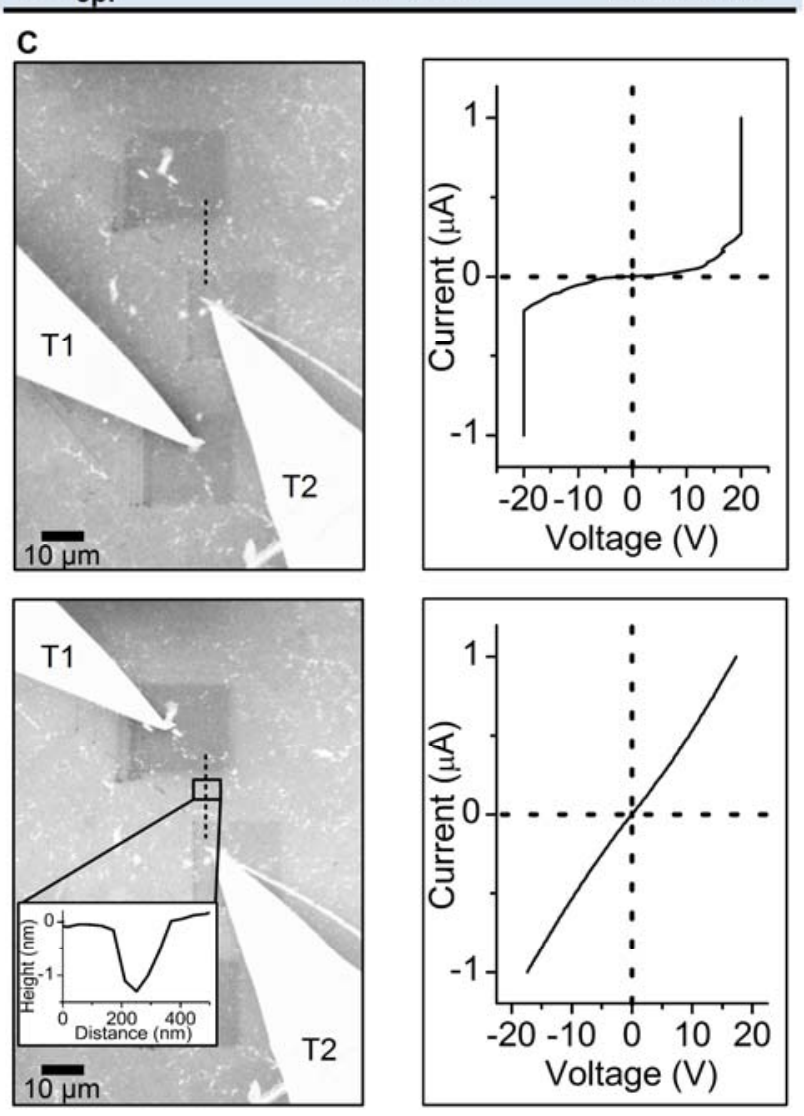


\section{References and Notes:}

1. M. Y. Han, B. Ozyilmaz, Y. B. Zhang, P. Kim, Phys. Rev. Lett. 98, 206805 (2007)

2. M. Orlita et al., Phys. Rev. Lett. 101, 267601 (2008).

3. X. Du, I. Skachko, A. Barker, E. Y. Andrei, Nat. Nanotechnol. 3, 491 (2008).

4. Y. B. Zhang, Y. W. Tan, H. L. Stormer, P. Kim, Nature 438, 201 (2005).

5. K. S. Novoselov et al., Science 306, 666 (2004).

6. C. Berger et al., J. Phys. Chem. B 108, 19912 (2004).

7. X. L. Li, X. R. Wang, L. Zhang, S. W. Lee, H. J. Dai, Science 319, 1229 (2008).

8. K. Nakada, M. Fujita, G. Dresselhaus, M. S. Dresselhaus, Phys. Rev. B 54, 17954 (1996).

9. J. Kedzierski et al., IEEE Trans. Electron Devices 55, 2078 (2008).

10. J. S. Moon et al., IEEE Electron Device Lett. 30, 650 (2009).

11. L. A. Ponomarenko et al., Science 320, 356 (2008).

12. L. S. Weng, L. Y. Zhang, Y. P. Chen, L. P. Rokhinson, Appl. Phys. Lett. 93, 093107 (2008).

13. L. Y. Jiao, L. Zhang, X. R. Wang, G. Diankov, H. J. Dai, Nature 458, 877 (2009).

14. G. Eda, G. Fanchini, M. Chhowalla, Nat. Nanotechnol. 3, 270 (2008).

15. X. S. Wu et al., Phys. Rev. Lett. 101, 026801 (2008).

16. J. T. Robinson, F. K. Perkins, E. S. Snow, Z. Q. Wei, P. E. Sheehan, Nano Lett. 8, 3137 (2008).

17. J. T. Robinson et al., Nano Lett. 8, 3441 (2008). 
18. G. Eda, C. Mattevi, H. Yamaguchi, H. Kim, M. Chhowalla, J. Phys. Chem. C 113, 15768 (2009).

19. R. Szoszkiewicz et al., Nano Lett. 7, 1064 (2007).

20. D. Wang et al., Appl. Phys. Lett. 91, 243104 (2007).

21. D. Wang et al., Adv. Funct. Mater. 19, 3696 (2009).

22. P. E. Sheehan, L. J. Whitman, W. P. King, B. A. Nelson, Appl. Phys. Lett. 85, 1589 (2004).

23. M. Yang, P. E. Sheehan, W. P. King, L. J. Whitman, J. Am. Chem. Soc. 128, 6774 (2006).

24. B. A. Nelson, W. P. King, A. R. Laracuente, P. E. Sheehan, L. J. Whitman, Appl. Phys. Lett. 88, 033104 (2006).

25. P. Vettiger et al., IEEE T. Nanotechnol. 1, 39 (2002).

26. C. Mattevi et al., Adv. Funct. Mater. 19, 2577 (2009).

27. C. Gomez-Navarro et al., Nano Lett. 7, 3499 (2007).

28. Epitaxial graphene layers were grown on the $\mathrm{C}$-face of $4 \mathrm{H}-\mathrm{SiC} . \mathrm{GO}_{\text {epi }}$ was obtained by direct oxidation of the epitaxial graphene films on (16 layers in Fig. 4A, and 4B, and 13 layers in Fig.4C) chip, as described in reference (15). TCNL was performed in $\mathrm{N}_{2}$ environment (Fig. 1 and 2) or ambient conditions (Fig. 3 and 4) using an AFM (Veeco Multimode III (Fig. 1 and 2) and IV (Fig. 3 and 4)) and custom made heated AFM probes (29) (nominal spring constant of $0.5 \mathrm{~N} \mathrm{~m}^{-1}$ ). During TCNL, the probe was heated while in contact with the GO surface at loading forces ranging between $120-230 \mathrm{nN}$. The calibration of the temperature at 
the top of the tip, $T_{\text {heater, }}$, and the estimation of the temperature at the tip-GO interface, $T_{\text {local }}$, is described in the online supporting material. All friction and electrical characterizations were performed at room temperature.

29. J. Lee et al., J. Microelectromech. Syst. 15, 1644 (2006).

30. H. C. Schniepp et al., J. Phys. Chem. B 110, 8535 (2006).

31. J. C. Meyer et al., Nature 446, 60 (2007).

32. T. Filleter et al., Phys. Rev. Lett. 102, 086102 (2009).

33. The thickness of the ribbon, $t_{\text {ribbon }}$, and the thickness of the sheet, $t_{\text {sheet }}$, have been inferred from the thickness of the corresponding GO films as reported in the online supplementary material.

34. This work has been supported by the National Science Foundation (CMDITR program DMR 0120967, MRSEC program DMR 0820382, and DMR-0706031), Department of Energy (DE-FG02-06ER46293 and PECASE), the Institute for Nanoscience at Naval Research Laboratory, the Office of Naval Research of the United States, and Georgia Institute of Technology (Georgia Tech Research Foundation, COE Cutting Edge Research Award, and COPE fellowship). This research was performed while Z.W. held a National Research Council Research Associateship Award at Naval Research Laboratory of the United States. ZW thanks Dr. Hua Qi at NRL for providing doped silicon wafers, evaporating gold layers on mica, and taking SEM images of GO sheets on gold and silicon substrates. 